\title{
PREDICTING PERFORMANCE INDICATORS USING BIM AND SIMULATION FOR A WALL ASSEMBLY LINE
}

\author{
Ryan Brown', Beda Barkokebas ${ }^{2}$,Chelsea Ritter ${ }^{3}$ and Mohamed Al-Hussein ${ }^{4}$
}

\begin{abstract}
Off-site home construction allows for the construction of building components to be completed in an off-site facility. The floors, walls, and roof are constructed on separate production lines, then shipped together to site for installation. This type of home construction presents a good opportunity to utilize lean manufacturing principles allied with simulation methods to better industrialize the home building process. This paper presents a case study of a well-known panelized residential home manufacturer, where the focus is the wall assembly line. Multiple key performance indicators (KPIs) are calculated in order to forecast production for each project and key result indicators (KRIs) are used to predict the outcomes of multiple projects. The predicted performance indicators are found through a simulation model of the production line using quantity take-offs extracted from BIM models. The analysis of these performance indicators will be used to evaluate project feasibility when the project is built in an off-site construction facility.
\end{abstract}

\section{KEYWORDS}

Lean construction, off-site construction, performance indicators, computer simulation, variability.

\section{INTRODUCTION}

The construction industry suffers from poor productivity and high levels of waste. The industrializing of construction has long been thought of as a solution to this (Koskela, 1992). Bjornfot and Stehn (2004) define industrialization as a streamlined process promoting efficiency and economic profit. By modelling construction after manufacturing, lean can be applied to construction to solve the shortcomings of traditional stick-built methods. Bjornfot and Stehn (2004) go on to define lean construction as a methodology aiming at streaming the whole construction process while product requirements are realized

1 M.Sc. Student, Department of Civil and Environmental Engineering, University of Alberta, Edmonton, Alberta, Canada, rabrown@ualberta.ca

2 PhD Student, Department of Civil and Environmental Engineering, University of Alberta, Edmonton, Alberta, Canada, barkokebas@ualberta.ca

3 PhD Student, Department of Civil and Environmental Engineering, University of Alberta, Edmonton, Alberta, Canada, critter1@ualberta.ca

4 Professor, Department of Civil and Environmental Engineering, University of Alberta, Edmonton, Alberta, Canada, mohameda@ualberta.ca 
during design, development and assembly. Therefore, the concept of industrialization and the philosophy of lean tie into one another seamlessly. Off-site construction derives its root from the manufacturing industry: entire stick-built construction projects are broken down into components that are easy to manufacture on factory production lines (Zhang et al, 2016).

Ritter et al. (2016) performed a study of the floor area of an off-site construction company (the same company used for the present case study) that focused on the analysis of directly and indirectly productive tasks to determine possible process improvements of the floor production line. By simulating the facility's current state operations, then applying multiple lean improvements to the model, productivity gains were quantified. The results of the future state simulation showed productivity increases and aided management in decision making.

Moghadam (2014) did a similar study of another modular home manufacturing facility. This study focused on the application of lean tools to the manufacturing process, and included studies of the floor, wall, and roof station timings to assist in production levelling. The use of multi-skilled labour was identified as a solution to balancing of the production lines since labourers could move between stations to maintain equal production rates.

Each of these studies provides valuable input on how to make a process more efficient, but does not provide an overall view of the whole manufacturing process. Performance indicators give a clearer representation of the benefits of lean since utilizing traditional accounting methodology is not always obvious (Bhasin, 2008). Performance indicators are used to measure the success of the manufacturing process. Key performance indicators (KPIs) are those indicators that focus on the aspects of organizational performance that are most critical for current and future success of the organization. Key result indicators (KRIs) summarize the activity of more than one team; it is a more overall look at the results of the activities that have taken place (Parmenter, 2010). Both of these performance measures are imperative for evaluating current and past production trends, as well as capturing the outcomes of the variability of project sizes. Through the use of performance indicators, lean improvements to the off-site manufacturing facility can be analysed.

The tools used to calculate these indicators are building information modelling (BIM) and computer simulation. BIM is a technology used to integrate the architectural and structural design, modularity concepts, and framing best practices into one model that helps the end-user during the decision-making process (Alwisy et al., 2012). Sacks et al. (2009, 2010) provided a conceptual framework for assessing the interconnections between lean and BIM and they identified 56 interactions through their developed matrix. Using the BIM model, it is possible to extract quantity take-offs that can be used in the simulation model.

Simphony.NET is an integrated environment for simulating construction activities that was developed by AbouRizk and Mohamed (2000). Simulation models are used to replicate complex operations and give valuable output regarding productivity, resource utilization, and material usage. Based on the output of the simulation model, it is possible to calculate these performance indicators and forecast manufacturing operations. 


\section{Motivation}

The objective of this paper is to use performance indicators to predict the outcomes of building the walls of a construction project in an off-site construction facility. Based on material quantities extracted from BIM models and the results generated from computer simulation, many performance indicators are evaluated. The predicted key performance indictors give insight into project specific production (cost and productivity): these indicators aid management in determining if a project is feasible. The predicted key result indictors are used to evaluate production outcomes over multiple projects (material usage, time and cost). By comparing actual production measures to the predicted performance indicators, management can determine material, budget, and schedule deviances.

\section{METHODOLOGY}

This research combines BIM modelling and discrete event simulation to predict the performance indicators of a wall production line for potential projects. Figure 1 shows the overall process used to extract information from BIM models, organize the information into a database, and feed this information to a simulation model to get data for calculating KPIs and KRIs. The information is extracted from each BIM model through a Dynamo script and parsed through a developed add-on in two stages: (1) sequencing and combining of all panels in the project into panels of maximum length of 40 feet, and (2) addressing each panel's attributes relevant to the simulation model as per Barkokebas et al. (2017). All information is stored in Microsoft Access and imported in the simulation model for the development of KPIs of each project.

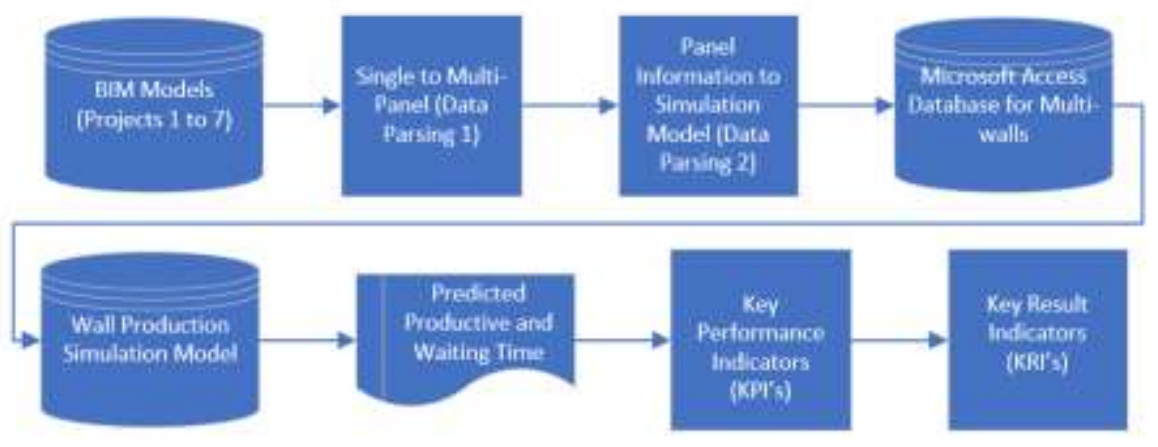

Figure 1: Process Diagram of Information Flow

The first step is to construct a current state simulation model of the wall production assembly line as shown in Figure 2. The simulation model was developed through discrete event simulation in Simphony.NET, a program developed by AbouRizk and Mohamed (2000). The current production process consists of ten stations as outlined in Table 1. To build the current state simulation model, each of the ten stations are broken down into multiple tasks with deterministic and heuristic durations dependent upon each panel's attribute such as number of openings, area, and use (exterior or interior). Each station also includes a probabilistic chance of delay that has a distributed duration. The tasks' durations are constant because of the high level of automation and standardization used in the 
manufacturing process. Simphony.NET is used to find the best fitting distribution for the delay durations based on the time study data gathered. Resource constraints for the number of labourers and equipment are also represented in the model. Altaf (2016) verifies and validates this simulation model in his doctoral dissertation. The inputs required for the simulation model are the number of window and door openings, studs, OSB sheets, corners and intersection and beam pockets. From this information the total wall area, number of multi-panel walls, and number of single panel walls are determined.

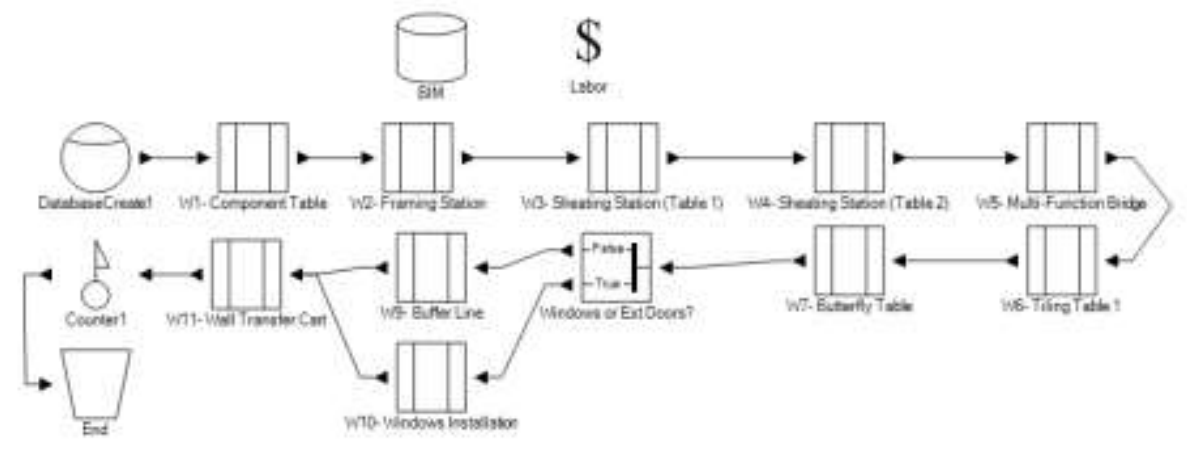

Figure 2: Wall Production Line Simulation Model

Table 1: Wall Production Stations

\begin{tabular}{|c|l|l|l|}
\hline Order & Station & Description & $\begin{array}{l}\text { Crew Size } \\
\text { (persons) }\end{array}$ \\
\hline 1 & Component table & $\begin{array}{l}\text { Opening rough-ins are assembled } \\
\text { prior to framing }\end{array}$ & 3 \\
\hline 2 & Framing station & $\begin{array}{l}\text { Studs, plates, and pre-assembled } \\
\text { components are nailed together }\end{array}$ & 2 \\
\hline 3 & Sheathing Station 1 & Label walls, and place hooks & 3 \\
\hline 4 & Sheathing Station 2 & $\begin{array}{l}\text { Place blocks, OBS sheathing and } \\
\text { vapour barrier }\end{array}$ & 3 \\
\hline 5 & Multi-function bridge & Nail sheathing & 1 \\
\hline 6 & Tilting table & Sheathing quality control & 2 \\
\hline 7 & Butterfly table & Place rods, and cut exterior walls & 2 \\
\hline 9 & Buffer Line & Backing and plastic wrap & 3 \\
\hline 10 & $\begin{array}{l}\text { Window/door } \\
\text { installation }\end{array}$ & $\begin{array}{l}\text { Installing windows and doors } \\
\text { where it applies }\end{array}$ & 5 \\
\hline 11 & Wall transfer & Flip wall & 1 \\
\hline
\end{tabular}

The next step is to gather all the take-off information from the BIM models. This is done by data parsing to gather the necessary information for every wall (single panel information). In order to efficiently construct the walls, the single panel walls must be arranged into multi-panel walls; this is done through the use of a greedy algorithm. This algorithm arranges single panel walls of the same size (2"x4", 2 "x6" or 2"x8") to be as close as possible to the machine limit of 40' in length. Data parsing is used again to gather the single and multi-panel data; this data is then exported to a Microsoft Access database that feeds the information into the simulation model. In this study, the BIM models of 5 
commercial projects and 1 residential house are used. The information extracted from the BIM models and used in the simulation model is shown in Table 2.

Table 2: Project Information

\begin{tabular}{|l|l|l|l|l|}
\hline Project ID & Project & $\begin{array}{l}\text { Number of } \\
\text { Multi-Panel } \\
\text { Walls }\end{array}$ & $\begin{array}{l}\text { Number of } \\
\text { Single Panel } \\
\text { Walls }\end{array}$ & $\begin{array}{l}\text { Total Wall Area } \\
\text { (SF) }\end{array}$ \\
\hline 1 & $\begin{array}{l}\text { BC Residential } \\
\text { Housing }\end{array}$ & 5 & 20 & 1785.33 \\
\hline 2 & $\begin{array}{l}\text { Kamsack Liquor } \\
\text { Store }\end{array}$ & 18 & 25 & 5113.37 \\
\hline 4 & $\begin{array}{l}\text { ATCO Site } \\
\text { Office/Washroom }\end{array}$ & 8 & 28 & 2006.18 \\
\hline 5 & $\begin{array}{l}\text { ATCO Small } \\
\text { Office/Washroom }\end{array}$ & 3 & 8 & 559.07 \\
\hline 6 & $\begin{array}{l}\text { ATCO Office } \\
\text { Building }\end{array}$ & 22 & 72 & 10587.35 \\
\hline 7 & Car Wash & 4 & 8 & 607.73 \\
\hline
\end{tabular}

Each project is put through the simulation model separately and for one thousand runs. All multi-walls of each project are released to station 1 at time zero. The simulation model outputs are: directly productive time ( $\mathrm{min}$ ) and waiting time (min) for each station. The hourly rate for crew workers is assumed to be $\$ 25 / \mathrm{hr}$ and the overhead rate for the facility is assumed to be $\$ 4500 / \mathrm{hr}$. From the simulation results, the predicted KPIs are calculated as shown in Table 3 . The predicted KRI values are calculated through the formulas shown in Table 4.

Table 3: Key Performance Indicators Formulas

\begin{tabular}{|l|l|}
\hline KPI & Formula \\
\hline Total Project Cost $(\$)$ & $=\left[\right.$ Directly Producitve Time $(\mathrm{min}) *$ Crew Size $\left.* 0.42\left(\frac{\$}{\mathrm{~min}}\right)\right]+\left[75\left(\frac{\$}{\min }\right) *\right.$ Lead Time $($ hr $\left.)\right]$ \\
\hline Productivity (SF/min) & $=\frac{\text { Total Wall Area }(\text { SF })}{\text { Project Lead Time }(\mathrm{min})}$ \\
\hline Project Cost (\$/SF) & $=\frac{\text { Total Project Cost }(\$)}{\text { Total Wall Area }(\mathrm{min})}$ \\
\hline
\end{tabular}

Table 4: Key Result Indicators Formulas

\begin{tabular}{|c|c|}
\hline KRI & Formula \\
\hline Total Material Usage & $\sum_{i=1}^{n}\left(\right.$ total wall area $\left.a_{\mathrm{i}}\right)$ \\
\hline Total Lead Time & $\sum_{i=1}^{n}$ (project project time $\left.{ }_{i}\right)$ \\
\hline Total Cost & $\sum_{i=1}^{n}\left(\right.$ project $\left.^{n} \operatorname{cost}_{\mathrm{i}}\right)$ \\
\hline
\end{tabular}




\section{RESULTS}

The simulation output for the productive and waiting times for each project are shown in Table 5 and Table 6. Figure 3 shows the total time per station for each project found by totalling the simulation results. The first spike in total time is due to significant waiting times found at stations 1 and 2 (component table and framing station, respectively). Wait times are highest here because all multi-walls are released at time zero to station 1, meaning there is a backlog of walls to begin with before they make their way down the assembly line. The second spike in total times occurs because of the long productive times of stations 9 and 10 (buffer line and window/door installation, respectively). Station 9 has a high productive time for the projects that need beam pockets, and is zero for projects that do not require them. The variability in the number of openings (windows and doors) strongly influences the productive time of station 10: if the multi-wall contains many openings, the productive time greatly increased. The simulation results identify stations that could be targeted for lean improvements to reduce project lead time. In this analysis, the stations with the highest wait times and productive times should be the focus of lean improvements. It is also important to note that the productive and wait times are highly variable due to the range of project sizes.

Table 5: Simulation Results - Productive Time

\begin{tabular}{|r|r|r|r|r|r|r|r|r|r|r|}
\hline \multicolumn{10}{|c|}{ Productive Time (min) } \\
\hline $\begin{array}{r}\text { Project } \\
\text { ID }\end{array}$ & @W1 & @W2 & @W3 & @W4 & @W5 & @W6 & @W7 & @W9 & @W10 & @W11 \\
\hline $\mathbf{1}$ & 7.70 & 12.21 & 6.50 & 8.48 & 3.44 & 1.70 & 2.83 & 0.00 & 32.34 & 2.70 \\
\hline $\mathbf{2}$ & 5.57 & 9.64 & 3.14 & 6.55 & 3.12 & 1.70 & 2.83 & 77.56 & 49.84 & 2.70 \\
\hline $\mathbf{4}$ & 11.55 & 13.21 & 6.72 & 5.23 & 3.14 & 1.70 & 2.83 & 152.97 & 51.74 & 2.70 \\
\hline $\mathbf{5}$ & 14.73 & 11.92 & 6.43 & 4.49 & 2.96 & 1.70 & 2.83 & 0.00 & 55.84 & 2.70 \\
\hline $\mathbf{6}$ & 9.98 & 15.53 & 6.78 & 3.47 & 3.75 & 1.70 & 2.83 & 205.04 & 72.45 & 2.70 \\
\hline $\mathbf{7}$ & 12.59 & 10.68 & 4.95 & 4.52 & 2.81 & 1.70 & 2.83 & 0.00 & 46.38 & 2.70 \\
\hline Average & 10.35 & 12.20 & 5.75 & 5.46 & 3.20 & 1.70 & 2.83 & 72.60 & 51.43 & 2.70 \\
\hline
\end{tabular}

Table 6: Simulation Results - Waiting Time

\begin{tabular}{|r|r|r|r|r|r|r|r|r|r|r|}
\hline \multicolumn{9}{|c|}{ Waiting Time (min) } \\
\hline $\begin{array}{r}\text { Project } \\
\text { ID }\end{array}$ & @W1 & @W2 & @W3 & @W4 & @W5 & @W6 & @W7 & @W9 & @W10 & @W11 \\
\hline $\mathbf{1}$ & 17.46 & 12.29 & 0.00 & 0.00 & 0.03 & 0.00 & 0.01 & 0.00 & 0.00 & 0.00 \\
\hline $\mathbf{2}$ & 69.61 & 67.63 & 0.00 & 0.00 & 0.25 & 0.00 & 0.09 & 0.00 & 0.00 & 0.24 \\
\hline $\mathbf{4}$ & 55.98 & 12.39 & 0.00 & 0.00 & 0.27 & 0.01 & 0.09 & 0.00 & 0.09 & 0.14 \\
\hline $\mathbf{5}$ & 14.90 & 0.38 & 0.00 & 0.00 & 0.02 & 0.00 & 0.02 & 0.00 & 0.00 & 0.08 \\
\hline $\mathbf{6}$ & 109.35 & 82.59 & 0.00 & 0.00 & 0.23 & 0.00 & 0.01 & 0.00 & 0.00 & 0.12 \\
\hline $\mathbf{7}$ & 23.59 & 7.39 & 0.00 & 0.00 & 0.35 & 0.02 & 0.15 & 0.00 & 0.00 & 0.00 \\
\hline Average & 48.48 & 30.45 & 0.00 & 0.00 & 0.19 & 0.01 & 0.06 & 0.00 & 0.02 & 0.10 \\
\hline
\end{tabular}




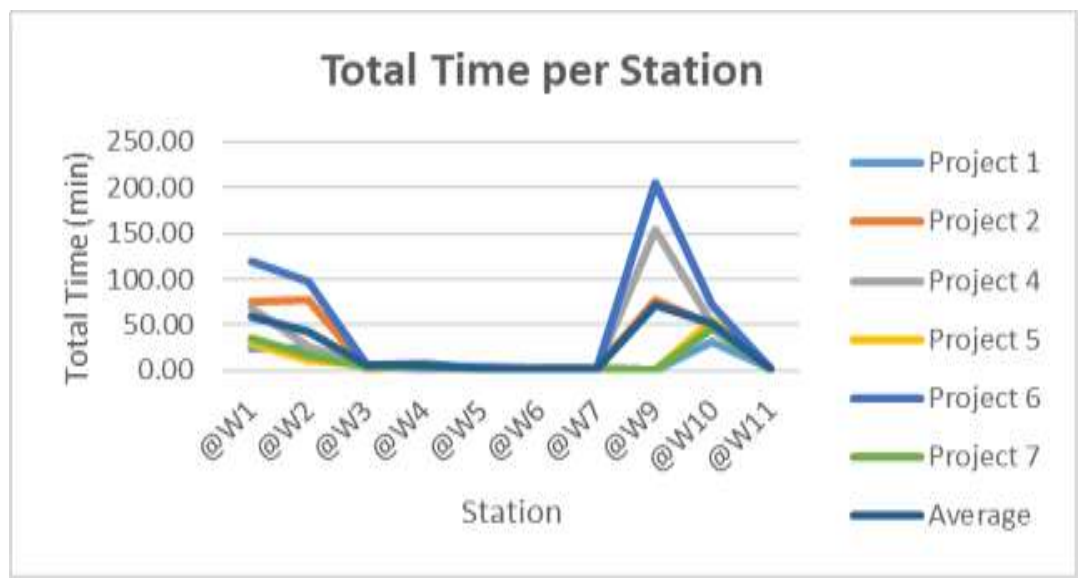

Figure 3: Total Time for Each Project

The predicted KPIs for the wall assembly line are shown in Table 7. These predicted values can be compared on a per project basis with actual KPIs once a project has been completed to determine material, schedule, and budget deviations. It was found that as project size increases, productivity increases and cost per square foot decreases, along with the obvious total project cost and time increase. This productivity increase and cost per square foot decrease occurs because wait times do not significantly increase when a larger project is being worked on. This is due to resource utilization of each station not being maximized. Once resource usage is maximized, wait times will increase, causing productivity to decrease and cost per square foot to increase. Therefore, productivity and cost savings can be gained by constructing projects with higher square footages of wall area, until resource utilization is exhausted. Figure 4 plots project size vs productivity with a linear trend line, which has $\mathrm{R}^{2}=0.6453$. Figure 5 plots project size vs cost with a linear trend line, which has $\mathrm{R}^{2}=0.5216$. These $\mathrm{R}$-squared values are seemingly low but do still provide proof of a correlation, given the small sample size. Furthermore, total project cost and project time vs project size (not shown graphically) were found to have $R^{2}=0.8245$ and $R^{2}=0.8260$, respectively. This reinforces results from the simulation model for the time and cost increases when constructing larger projects.

Table 7: Predicted Key Performance Indicators

\begin{tabular}{|r|r|r|r|r|r|r|}
\hline Project & $\begin{array}{l}\text { Project } \\
\text { Size (SF) }\end{array}$ & $\begin{array}{l}\text { Productivity } \\
\text { (SF/min) }\end{array}$ & $\begin{array}{l}\text { Direct } \\
\text { Cost } \mathbf{( \$ )}\end{array}$ & $\begin{array}{l}\text { Indirect } \\
\text { Cost (\$) }\end{array}$ & $\begin{array}{l}\text { Project } \\
\text { Cost (\$) }\end{array}$ & \multicolumn{1}{l|}{$\begin{array}{l}\text { Cost } \\
\mathbf{( \$ / S F )}\end{array}$} \\
\hline $\mathbf{1}$ & 1785.33 & 16.58 & 61.07 & 8076.57 & 8137.63 & 4.56 \\
\hline $\mathbf{2}$ & 5113.37 & 17.02 & 154.50 & 22534.71 & 22689.21 & 4.44 \\
\hline $\mathbf{4}$ & 2006.18 & 6.25 & 263.72 & 24057.65 & 24321.37 & 12.12 \\
\hline $\mathbf{5}$ & 559.07 & 4.70 & 74.24 & 8924.97 & 8999.21 & 16.10 \\
\hline $\mathbf{6}$ & 10587.35 & 20.50 & 336.08 & 38738.45 & 39074.54 & 3.69 \\
\hline $\mathbf{7}$ & 607.73 & 5.04 & 64.63 & 9048.40 & 9113.03 & 15.00 \\
\hline
\end{tabular}




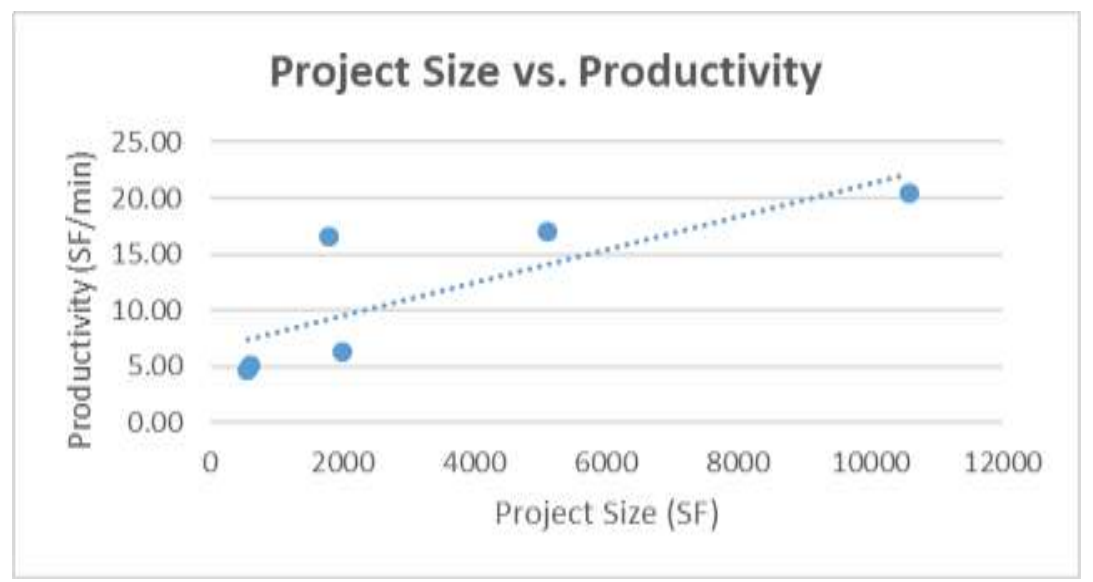

Figure 4: Productivity of Each Project

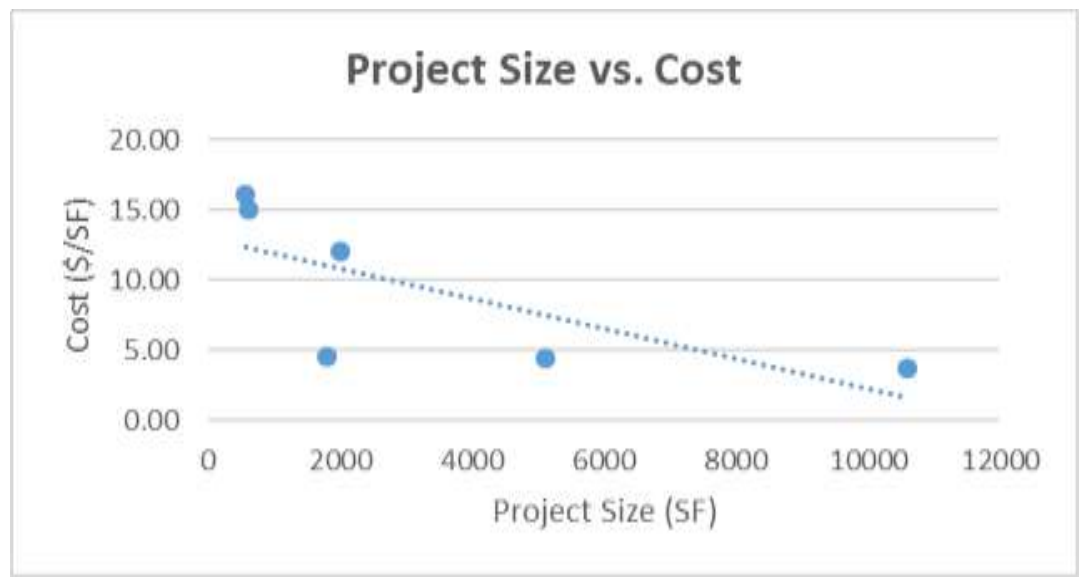

Figure 5: Cost of Each Project

Since each project produces a high variability of results further analysis into production over a specified time period is necessary. The predicted KRI values are shown in Table 8 . These values are a summation of material, time, and cost requirements for completing all six projects. By comparing the predicted KRI values to actual material, time, and cost outcomes, production can be evaluated in terms of material, schedule, and budget deviations over the entire production period. Table 9 defines how to interpret the deviations of predicted vs actual KRI values. Evaluating production over numerous projects gives an overall analysis of facility performance rather than focusing on project-specific production.

Table 8: Predicted Key Result Indicators

\begin{tabular}{|l|l|}
\hline Total Material Usage (SF) & 20659.03 \\
\hline Total Project Time (min) & 1485.08 \\
\hline Total Cost (\$) & 112335.00 \\
\hline
\end{tabular}


Table 9: Key Result Indicator Interpretation

\begin{tabular}{|l|l|}
\hline KRI & $\Delta=\mathbf{K R I}_{\text {actual }}-\mathbf{K R I} \mathbf{I r e d i c t e d ~}$ \\
\hline Total Material Usage & $+\Delta=$ material waste \\
& $-\Delta=$ material saving \\
\hline Total Production Time & $+\Delta=$ schedule delay \\
& $-\Delta=$ ahead of schedule \\
\hline Total Cost & $+\Delta=$ over budget \\
& $-\Delta=$ under budget \\
\hline
\end{tabular}

\section{LIMITATIONS AND FUTURE WORK}

This research is limited by the separate simulation of each project. This method does not completely reflect actual production methods of releasing a new project to the floor once there is resource availability at the first station. The method of simulating production over multiple projects is preferable to simulating projects one at a time because rarely will a single project have the entirety of the factory floor. If only one project is simulated, the waiting time will only be accumulated due to the backlog of multi-walls of one project and not due to the wait time of projects catching up to one another. Calculating performance indicators based on only a single project will lead to a slight overestimate of production and underestimated costs. In the future, it would be useful to simulate production continuously over all projects in order to determine the additional wait time that would be accumulated. Furthermore, it would be ideal to simulate a larger number of BIM models in order to prove a stronger correlation between productivity and cost vs project size. If enough projects have been simulated, predictive data analysis techniques such as regression, clustering, or time series analysis can be used to predict the KPIs of possible projects without having to construct a BIM model to be used in the computer simulation model. Through the data analysis of performance indicators, it will be possible to efficiently evaluate the feasibility of potential projects in an off-site construction facility. Another limitation of this research is the focus on only the wall production line. In the future the same analysis should be done for the floor and roof production lines in order to determine the performance indicators of the whole projects, rather than just those for the wall production line.

\section{CONCLUSION}

Through BIM modelling and computer simulation the productive and waiting times for the wall assembly line was determined for six different projects. Using these times and information from the BIM model, numerous key performance indicators were predicted. Upon analysis of these KPIs it was found that as project size increased, productivity $(\mathrm{SF} / \mathrm{min})$ and cost $(\$ / \mathrm{SF})$ decreased. Additionally, the predicted key result indicators for construction of all six projects was calculated. Based on these results, the feasibility and outcomes of producing walls through off-site construction can be measured. On a per project basis the predicted KPI values can be used to determine the schedule, budget, and material implications. While the predicted KRI values give an overview of the total material, schedule, and budget requirements of production over several projects. 


\section{ACKNOWLEDGEMENTS}

The authors would like to thank everyone at the case study company for allowing us to observe their actions at the facility in order to collect the data needed for this study. We would like to specifically thank Antonio Cavalcante Araujo Neto, Mohammed Sadiq Altaf, and Mahmud Abushwereb for their invaluable collaboration in this work.

\section{REFERENCES}

AbouRizk, S., and Mohamed, Y. (2000). "Simphony-an integrated environment for construction simulation." Proc., 2000 Winter Simulation Conference (Cat. No.00CH37165), 2, Orlando, Fl., USA, 1907-1914.

Altaf, M. (2016). Integrated Production Planning and Control System for Prefabrication of Panelized Construction for Residential Building. Ph.D. The University of Alberta.

Alwisy, A., Al-Hussein, M., and Al-Jibouri, S. H. (2012). "BIM approach for automated drafting and design for modular construction manufacturing." Proc., Computing in Civil Engineering 2012, ASCE, Reston, VA, 221-228.

Barkokebas, B., Zhang, Y., Ritter, C., and Al-Hussein, M. (2017). "Building information modelling and simulation integration for modular construction manufacturing performance improvement." Proc., European Modelling and Simulation Symposium, Barcelona, Spain, 409-415.

Bhasin S. (2008). "Lean and performance measurement," Journal of Manufacturing Technology Management, vol. 19, no. 5, pp. 670-684.

Bjornfot, A. and Stehn, L. (2004): Industrialization of Construction -A Lean Modular Approach. IGLC 12, Elsinore, Denmark

Koskela, L., 1992. Application of the New Production Philosophy to Construction. Technical Report No. 72, CIFE Department of Civil Engineering, Stanford University.

Parmenter, D. (2010). Key Performance Indicators: Developing, Implementing, and Using Winning KPIs, 2nd ed., John Wiley \& Sons, New Jersey, USA.

Sacks, R., Dave B. A., Koskela, L., and Owen, R. (2009). "Analysis framework for the interaction between lean construction and building information modeling", Proceedings for the 17th annual conference of the international group for lean construction, Taipei, Taiwan, 221-234.

Sacks, R., Koskela, L., Dave B. A., and Owen, R. (2010). "Interaction of lean and building information modeling in construction", Journal of construction engineering and management, 136(9), PA, 968-980.

Zhang, Y., Fan, G., Lei, Z., Han, S., Raimondi, C., Al-Hussein, M., Bouferguene, A. (2016). "Lean-based diagnosis and improvement for off-site construction factory manufacturing facilities." ISARC. Proc., International Symposium on Automation and Robotics in Construction. Vol. 33. Vilnius Gediminas Technical University, Department of Construction Economics \& Property, 1090-1098. 